\title{
Transcription Profiles of Aortic Smooth Muscle Cells from Atherosclerosis-Prone and -Resistant Regions in Young Apolipoprotein E-Deficient Mice before Plaque Development
}

\author{
Tim Van Assche ${ }^{a}$ Jan Hendrickx ${ }^{a}$ Herta M. Crauwels ${ }^{a}$ Pieter-Jan Guns ${ }^{a}$ \\ Wim Martinet $^{b}$ Paul Fransen ${ }^{b}$ Martine Raes ${ }^{c}$ Hidde Bult $^{a}$

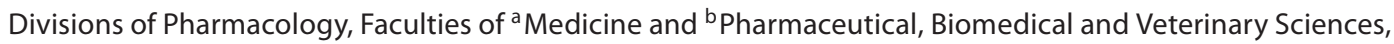 \\ University of Antwerp, Wilrijk, and 'Laboratory of Biochemistry and Cellular Biology, University of Namur (FUNDP), \\ Namur, Belgium
}

\section{Key Words}

Atherosclerosis $\cdot$ Smooth muscle cells · Microarray •

Apolipoprotein E-deficient mice

\begin{abstract}
Background/Aims: Site-specific atherosclerosis is generally attributed to differential gene expression in endothelial cells. We investigated whether the transcriptome of smooth muscle cells is different between atherosclerosis-prone and atherosclerosis-resistant regions in apolipoprotein E-deficient (apoE-/-) mice before plaque development, and in C57BI/6 mice. Methods: De-endothelialized aortas (both strains: 3 males, 3 females, age 4 months) were divided into atherosclerosis-prone (AA: ascending aorta, aortic arch and proximal $2 \mathrm{~mm}$ of thoracic aorta) and -resistant (CTA: central thoracic aorta, i.e. $6 \mathrm{~mm}$ distal from the proximal $2 \mathrm{~mm}$ ) regions. The transcriptome of these two regions was compared using whole-genome mouse microarrays. Results: Microarray analysis revealed differential expression $(>2$-fold difference) of 70 and 244 genes in $\mathrm{C} 57 \mathrm{BI} / 6$ and apoE-/- mice. This was confirmed for 6 genes using the real-time quantitative polymerase chain reaction. Up- or downregulation in the AA was observed for 33 and 37 genes in C57BI/6, and for 186 and 58 genes in apoE-/- mice, respectively. The 201
\end{abstract}

genes that showed exclusively differential expression in apoE-/- mice were related to atherosclerotic processes, such as cell adhesion, proliferation, differentiation, motility, cell death, lipid metabolism and immune responses. Conclusion: Our findings indicate that smooth muscle cells display an altered transcriptome at atherosclerosis-prone locations before actual lesion development.

Copyright $\odot 2010$ S. Karger AG, Basel

\section{Introduction}

Early development of atherosclerotic plaques is determined by biochemical stimuli, including growth factors, cytokines and levels of cholesterol and (oxidized) lipoproteins, as well as biomechanical stimuli. The latter originate from differences in wall tension or blood flow patterns at branching points, the outer wall of bifurcations, and the inner wall of curvatures in arteries. Regions with disturbed flow patterns are prone to develop atherosclerosis and are therefore called 'atherosclerosis-

T.V.A. and J.H. contributed equally to this study.

\section{KARGER}

Fax +4161306 1234 E-Mail karger@karger.ch www.karger.com
(C) 2010 S. Karger AG, Basel 1018-1172/11/0481-0031\$38.00/0 www.karger.com/jvr
Prof. Dr. Hidde Bult

Division of Pharmacology, University of Antwerp, CDE

Universiteitsplein 1

BE-2610 Wilrijk (Belgium)

Tel. +32 3820 2738, Fax +32 3820 2567, E-Mail hidde.bult@ua.ac.be 
prone', whereas segments with steady laminar unidirectional flow are less susceptible and therefore named 'atherosclerosis-resistant' $[1,2]$. The site-specific development of atherosclerotic lesions is also observed in murine models for atherosclerosis [3]. Apolipoprotein E-deficient (apoE-/-) mice preferentially exhibit lesion formation in the aortic root and arch, and the proximal and distal part of the thoracic aorta [4-6].

Human aortic [7] and umbilical vein [8] endothelial cells exposed to disturbed flow patterns showed upregulated mRNA levels of proinflammatory, proapoptotic and procoagulant genes. Therefore, these endothelial cells show a 'proatherogenic phenotype', whereas steady laminar flow raised expression of atheroprotective genes, such as superoxide dismutase 1 and endothelial cell nitric oxide synthase [9]. These findings suggest that the shear stressdependent pro- or antiatherogenic phenotype of endothelial cells could explain the site specificity of atherosclerosis. In addition to differences in flow, atherosclerosisprone regions display a larger diameter or a geometry that deviates from a circle (at branch points). As a consequence, endothelial cells and smooth muscle cells (SMCs) endure increased wall tension in these locations as compared to atherosclerosis-resistant regions $[10,11]$. Indeed, focal adhesion kinase phosphorylation, which plays a role in cell adhesion, is enhanced in endothelial cells and SMCs of rabbit aortas exposed to a steady stretch of $150 \mathrm{~mm} \mathrm{Hg}$ for $24 \mathrm{~h} \mathrm{[12]}$. This finding indicates that in atherosclerosisprone regions SMCs could be affected by biomechanical stimuli as well. Some in vitro evidence also suggests that SMCs respond to shear stress. Cultured arterial SMCs subjected to increasing shear stress show less cell proliferation, whereas decreasing shear forces [13] or pulsatile turbulent shear [14-16] stimulated SMC mitosis. This suggests that the cell cycle is arrested in SMCs in segments with laminar flow, whereas it is promoted in atherosclerosis-prone regions. Thus, in accordance with the endothelium, the shear-determined phenotype of SMCs correlates with the site specificity of atherosclerosis.

However, the effects of shear stress and wall tension on SMCs have only been studied in vitro, and it remains to be determined whether comparable indications can be found in vivo. Therefore, we compared SMC gene expression in an atherosclerosis-prone and an atherosclerosisresistant region. This was performed before plaque development, since subendothelial accumulation of monocytes, foam cells, T cells and SMCs with a synthetic phenotype will inevitably change the 'overall' gene expression profile of the vessel wall as soon as atherosclerosis develops [17]. RNA was collected from the lesion-free, endothelium-denuded aortic arch (AA; atherosclerosisprone) and central thoracic aorta (CTA; atherosclerosisresistant) of young (4 months) apoE-/- and wild-type (C57Bl/6) mice. Each RNA extract was divided into two aliquots: one was pooled for genome-wide microarray analysis; the other half was stored for validation of gene expression by means of the real-time quantitative polymerase chain reaction (RT-qPCR). The impact of the location was studied in $\mathrm{C} 57 \mathrm{Bl} / 6$ mice, whereas the combination of location and hypercholesterolemia was evaluated in apoE-/- mice.

\section{Materials and Methods}

\section{Animals}

The studies were approved by the ethical committee of the University of Antwerp. C57Bl/6 and apoE-/- mice (back-crossed into the $\mathrm{C} 57 \mathrm{Bl} / 6$ background for more than 10 generations) were kept on a regular chow diet and given tap water ad libitum throughout the study. Plaque size was evaluated in apoE-/- mice at the age of $6(n=5), 14(n=5), 18(n=5)$ and $22(n=9)$ months. SMC gene expression was analyzed (microarray) and validated (RT-qPCR) at 4 months (both strains, $\mathrm{n}=6,3$ males, 3 females); for confirmation, a second sample of both strains $(n=5)$ was analyzed at 4 months.

\section{Isolation of Aorta}

Mice were anesthetized with sodium pentobarbital (Nembutal $^{\circledR}, 75 \mathrm{mg} / \mathrm{kg}$, i.p.). The aorta was carefully excised and cleaned from adherent tissue. For plaque size analysis, the aorta was systematically sectioned as depicted in figure 1: the first millimeter of the aorta after the heart is defined the aortic root; the thoracic aorta was divided into $5 \times 2 \mathrm{~mm}$ segments (TA1-5) starting approximately $3 \mathrm{~mm}$ from the origin of the left subclavian artery (where the azygos vein crosses over the aorta) down to the diaphragm.

For gene expression studies, the aorta was perfused with $4 \mathrm{ml}$ Krebs-Ringer solution $\left([\mathrm{mM}] \mathrm{NaCl} 118, \mathrm{KCl} 4.7, \mathrm{CaCl}_{2} 2.5\right.$, $\mathrm{KH}_{2} \mathrm{PO}_{4} 1.2, \mathrm{MgSO}_{4} 1.2, \mathrm{NaHCO}_{3} 25$, CaEDTA 0.025 and glucose 11.1) containing $0.01 \%$ Triton $X-100$ to remove the endothelium and rinsed with $10 \mathrm{ml}$ Krebs-Ringer solution without TritonX-100. The atherosclerosis-prone region (AA: aortic arch and the proxi$\mathrm{mal} 2 \mathrm{~mm}$ of the thoracic aorta) and atherosclerosis-resistant region (CTA: central thoracic aorta $=6 \mathrm{~mm}$ distal from the proximal segment of the thoracic aorta; fig. 1) were placed in $350 \mu \mathrm{l}$ Trizol reagent within 2 min after starting the perfusion. Successful removal of the endothelium was validated by RT-qPCR of CD31, an endothelial cell marker.

\section{Plaque Size Analysis}

Each segment was placed in paraformaldehyde (4\%, $24 \mathrm{~h})$, embedded in optimum compound temperature (OCT) and kept at $-80^{\circ} \mathrm{C}$ for further analysis. From each segment, 3 transverse sections $(6 \mu \mathrm{m})$ - taken at intervals of $150 \mu \mathrm{m}$ (aortic root) or 250 $\mu \mathrm{m}$ (all other segments) - were stained for elastin (Verhoeff-Van Gieson). The cross-sectional area of the intima was quantified by 


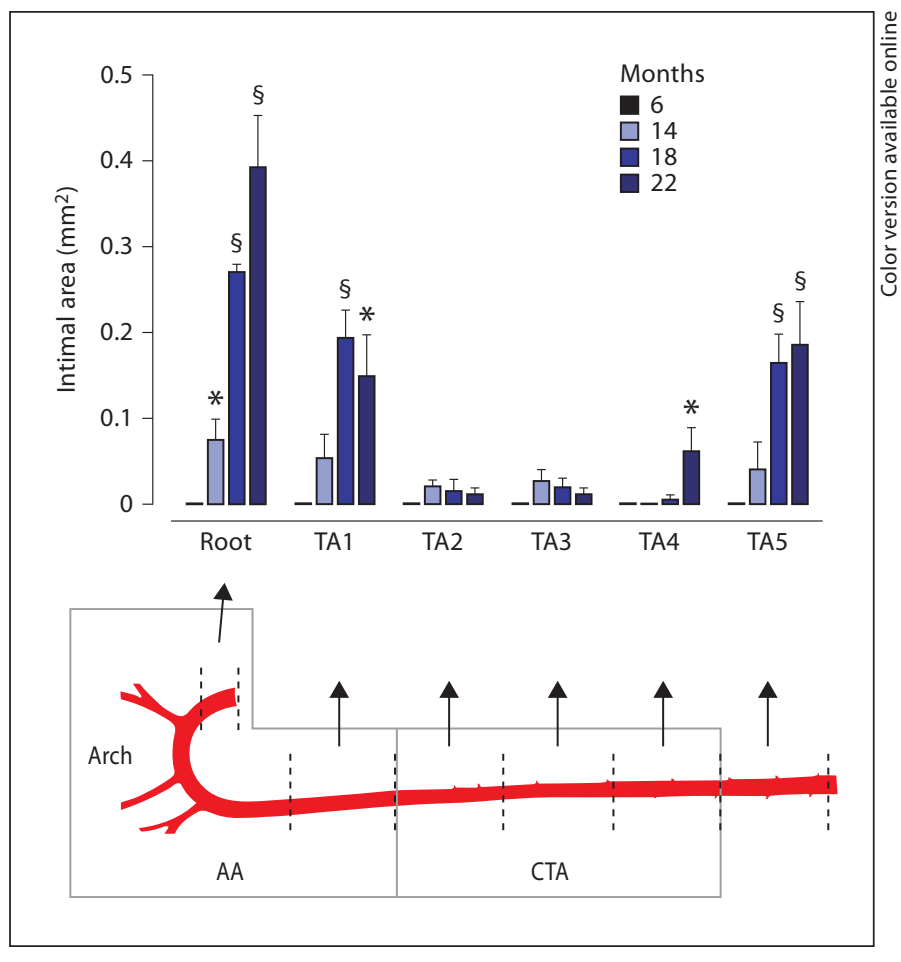

Fig. 1. Bar graph representing the age-dependent rise in the crosssectional area of the intima in the aortic root and the thoracic aorta of apoE-/- mice on regular chow. This shows that atherosclerosis develops preferentially in specific regions. At the age of 6 months, the aorta was plaque free, but at 14 months it showed lesions in the aortic root, the aortic arch (AA) and the proximal $2 \mathrm{~mm}$ of the AA, and in the distal thoracic aorta. These regions are therefore designated 'atherosclerosis-prone'. The central thoracic aorta (CTA) remained largely plaque free and is therefore called 'atherosclerosis-resistant'. SMC gene expression of endotheliumdenuded atherosclerosis-prone (AA) and -resistant (CTA) regions was compared at the age of 4 months, i.e. before plaque development. Data represent means $\pm S E M ;{ }^{*} \mathrm{p}<0.05,{ }^{\S} \mathrm{p}<0.01$, different from zero, one-sample t test.

means of point counting using a grid on the microscope eyepiece [18]. The average of the 3 measurements was used for further analysis.

\section{RNA Isolation}

Aortic segments were immediately cut into small pieces and lysed in $350 \mu \mathrm{l}$ Trizol reagent (Invitrogen, Merelbeke, Belgium). Subsequently, RNA was purified using the RNeasy MinElute kit (Qiagen, Antwerp, Belgium) and collected in $25 \mu$ l RNase-free water. RNA quality was tested by electrophoresis using the Agilent Bioanalyser. All RNA samples had an RNA integrity number between 7.5 and 7.7. RNA extracts $(12 \mu \mathrm{l})$ from the 6 mice were pooled and used for microarray analysis of the atherosclerosisprone and -resistant region; the remaining RNA from individual mice was stored separately and used to validate the microarray results with RT-qPCR.

\section{RNA Amplification, Labeling and Microarray}

Isolated RNA was amplified and labeled in duplicate using the Low RNA Input Fluorescent Linear Amplification Kit (Agilent) at the VIB MicroArray Facility (Leuven, Belgium, www.microarrays. be). It features a single amplification, two-color labeling method to create cyanine 3 - and cyanine 5-labeled cRNA. One sample was labeled with cyanine 3 and one with cyanine 5 . After labeling, both samples were combined, and cRNA was hybridized to an AgilentMouse-Whole Genome Array (Ag-Mo-WG-G4122A). Hybridization of cRNA to the microarray oligos occurred at $65^{\circ} \mathrm{C}$ while rotating the microarray slide $(4 \mathrm{rpm})$ during $17 \mathrm{~h}$, followed by washing according to the manufacturer's guidelines. Finally, the microarray slide was scanned using an Agilent Scanner, and the resulting two-color TIF image was analyzed using Agilent Feature Extraction Software 8. The light intensity of each gene in the duplicate slides was compared. When intensities differed from each other, the result for that gene was excluded. Otherwise, it was examined whether the mean intensity of that gene in the CTA sample of both microarrays was different from the mean for that gene in the AA sample by means of Student's t test $(\alpha=0.01)$. Finally, only intensity differences greater than 2-fold were considered. Using freely available software (Ease version 2.0), differentially expressed genes were categorized in biological processes.

The microarray data are available to the public via the National Center for Biotechnology Information Gene Expression Omnibus at: http://www.ncbi.nlm.nih.gov/geo/query/acc.cgi?acc= GSE13865.

\section{Real-Time Quantitative Polymerase Chain Reaction}

Relative expression of genes of interest was evaluated using the Two Step RT-qPCR Core kit (Eurogentec, Seraing, Belgium). RNA was converted into cDNA (Reverse Transcriptase Core kit, Eurogentec), then subjected to quantitative PCR (qPCR Core kit, Eurogentec) on an ABI 7300 Instrument (Applied Biosystems, Foster City, Calif., USA) using primers and probes shown in table 1 . The relative expression of mRNA species was calculated using the comparative threshold cycle $(\mathrm{Ct})$ method using $\beta$-actin and hypoxanthine guanine phosphoribosyl transferase as reference genes; the mean value of the 6 CTA extracts was set to 1 using the $2^{-\Delta \Delta C t}$ method [19].

\section{Statistical Analysis}

All results are expressed as means \pm SEM; $n$ represents the number of mice. A $5 \%$ level of significance was selected. A onesample t test was used to verify whether the cross-sectional area of the intima was different from zero. Differences among regions and sexes were analyzed using a repeated-measures ANOVA of the $-\Delta \Delta$ Ct values with segment (AA vs. CTA) as within-subject factor and gender (male or female) as between-subjects factor. Deming regression on ${ }^{2}$ log-transformed microarray and RT-qPCR results were used to assess the relationship between these methods.

\section{Results}

\section{Plaque Size Analysis}

In apoE-/- mice, plaques were not observed in any segment studied at the age of 6 months. After 14 months, however, atherosclerotic lesions had developed and their size 
Table 1. Forward and reverse primers, and fluorogenic probes used in RT-qPCR

\begin{tabular}{ll}
\hline Gene & Sequence or code \\
\hline $\begin{array}{l}\text { B-Actin } \\
\quad \text { Forward primer }\end{array}$ & \\
$\quad$ Reverse primer & GCT CTG GCT CCT AGC ACC AT \\
$\quad$ Taqman probe & GCC ACC GAT CCA CAC AGA GT \\
Hypoxanthine guanine phosphoribosyl transferase & FAM-ATC AAG ATC ATT GCT CCT CCT GAG CGC-TAMRA \\
$\quad$ Forward primer & TCC TAT GCC GAG GAT TTG GAA \\
$\quad$ Reverse primer & FAM-CTT TCA GTC CTG TCC ATA ATC AGT CCA TGA GG-TAMRA \\
Taqman probe & Mm00436767_m1 (Applied Biosystems) \\
Secreted phosphoprotein 1 & Mm00431827_m1 (Applied Biosystems) \\
Amyloid beta precursor protein & Mm00437612_m1 (Applied Biosystems) \\
Sodium potassium ATPase, beta 1 subunit & Mm00481536_m1 (Applied Biosystems) \\
Sarcolipin & Mm00650702_m1 (Applied Biosystems) \\
Homeobox B7 & Mm00444340_m1 (Applied Biosystems) \\
Fatty acid-binding protein 1 &
\end{tabular}

Table 2. List of genes that were up- or downregulated in the AA versus the CTA of C57Bl/6 and apoE-/- mice, or both strains (common)

\begin{tabular}{|c|c|c|}
\hline Strain & Up & Down \\
\hline C57Bl/6 & $\begin{array}{l}\text { 2610027K06Rik; 4833415N18Rik; 4930544G21Rik; 5033428I22Rik; } \\
\text { BC049816; D630004D15Rik; Dner; Enpp2; Gdf2; Hrasls; Kif1a; Matn3; } \\
\text { Wif1 }\end{array}$ & $\begin{array}{l}\text { 4921525H12Rik; AI646519; Angptl1; D830007B15Rik; Hoxb8; } \\
\text { Junb; LOC620807; LOC635091; Wnt2; XM_620048; Ptpn20; } \\
\text { Rgs17 }\end{array}$ \\
\hline Common & $\begin{array}{l}\text { 1600029D21Rik; 2210407C18Rik; A930010C08Rik; Atp1b1; Cyt1; Dspg3; } \\
\text { Flrt3; Fndc5; Gsta3; Lnx1; Myl7; Pln; Ren1; Slc38a4; Sln; Sncg; Stc2; Tcf21; } \\
\text { Thbd; Tnnt2 }\end{array}$ & $\begin{array}{l}\text { 1600015H20Rik; Alb1; Aldh1a3; Art3; Avpr1a; BC034076; } \\
\text { Bmper; Btc; Calcrl; Fhl2; Gpsm2; Hoxa5; Hoxa7; Hoxb3; } \\
\text { Hoxb5; Hoxb6; Hoxb7; Hoxc6; Inmt; Lgi2; Mup1; Mup3; } \\
\text { Mup4; NAP102507-1; Pax1 }\end{array}$ \\
\hline apoE-l- & $\begin{array}{l}\text { 1110008I14Rik; 1500001A10Rik; 1700110N18Rik; 2010002N04Rik; } \\
\text { 2810046M22Rik; 5033428I22Rik; 9030611O19Rik; A_52_P517668; } \\
\text { A930008A22Rik; A930008K15Rik; Abca1; Abcb1a; Abcg1; Adam23; } \\
\text { Adam8; Ahsg; AI549825; AK045479; AK046514; AK046686; AK078599; } \\
\text { AK089297; Akp2; Aldh1a2; Amph; App; Aqp1; Arhgap25; Atp6v0d2; } \\
\text { AY248756; B230106I24Rik B430119L13Rik; B430320C24Rik; BC023928; } \\
\text { BC087964; Bok; Brip1; Bst1; C3; C630002N23Rik; C77080; Cacnb4; Cd5l; } \\
\text { Cdkn2b; Celsr1; Clec1b; Clec7a; Clstn2; Cmya4; Cox6a2; Cplx2; Crym; } \\
\text { Csf2rb2; Csrp3; Cst9; Cthrc1; Ctss; Cxcl7; Cxcl9; Cyp2s1; D11Ertd759e; } \\
\text { D130058I21Rik; D330050I23Rik; D3Bwg0562e; Dlgap1; Dnmt3a; } \\
\text { E130010M05Rik; Edn1; Efemp1; Esrrg; F730004D16Rik; Fetub; Fgf10; } \\
\text { Frzb; Fxyd3; Galnt6; Gas6; Gcnt1; Gpm6a; Gpnmb; Gsta1; Igfbp2; Igfbp3; } \\
\text { Igfbp4; Igfbp5; Il18bp; Il7r; Inhbb; Itga6; Itgax; Kdr; Krt1-18; Krt1-19; } \\
\text { Krt1-23; Krt2-7; Krt2-8; Lama2; Lars2; Lgals3; Lgals7; Lisch7; LOC224833; } \\
\text { LOC433431; Lrat; Lrrn3; Ltbp2; Lum; Lypdc1; Mb; Meox1; Mgat3; } \\
\text { Mmp12; Mpeg1; Msln; Myh8; Myl4; Nkx6-2; Npr3; Nt5e; Odz4; Palmd; } \\
\text { Pamci; Pappa; Pcdh9; Peg3; Plekha6; Polydom; Popdc2; Prg4; Psap; Ptn; } \\
\text { Ptprb; Ptprf; Ptx3; Ren2; Rgs1; Rhpn2; Rnf128; Rragd; Sdc3; Serpinb6b; } \\
\text { Slc15a3; Slc23a3; Slc26a3; Slc37a2; Slc39a8; Slco2a1; Smoc1; Smpx; Sox9; } \\
\text { Spp1; Syngr1; TC1307854; Tmem26; Tnfrsf11b; Tnni3; Tpm1; Trdn; } \\
\text { Trem2; Unc5b; Upk1b; Upk3b; Vcam1; Vil2; Wfdc2; Wt1; Zfp185; Zic1 }\end{array}$ & $\begin{array}{l}\text { 1100001G20Rik; 2610034M16Rik; 2900093B09Rik; } \\
\text { 3110032G18Rik; AB080658; Agxt; AK027978; AK040144; } \\
\text { C1qtnf3; Calml4; Col8a2; Cpb1; ENSMUST00000081396; } \\
\text { Esm1; F2; Fabp1; Hhip; Hoxc8; Kng1; LOC329416; } \\
\text { LOC433053; Lrrn1; Mybpc2; NAP112201-1; Pde6h; Rgs2; } \\
\text { Saa3; Sema3a; Sfrp4; Slc22a1; Slc22a2; TC1324209; Zfp60 }\end{array}$ \\
\hline
\end{tabular}


Fig. 2. Ratio-intensity plots of the average ${ }^{2} \log$ ratio between the AA and the CTA versus the average ${ }^{2} \log$ intensity for the $\mathrm{mi}$ croarray results of the the apoE-/- (a) and $\mathrm{C} 57 \mathrm{Bl} / 6$ mice (b). In $\mathrm{C} 57 \mathrm{Bl} / 6$ mice 70 genes and in ApoE-/- mice 246 genes showed a greater than 2-fold statistically significant ratio difference (Student's $\mathrm{t}$ test, $\mathrm{p}<0.01)$.

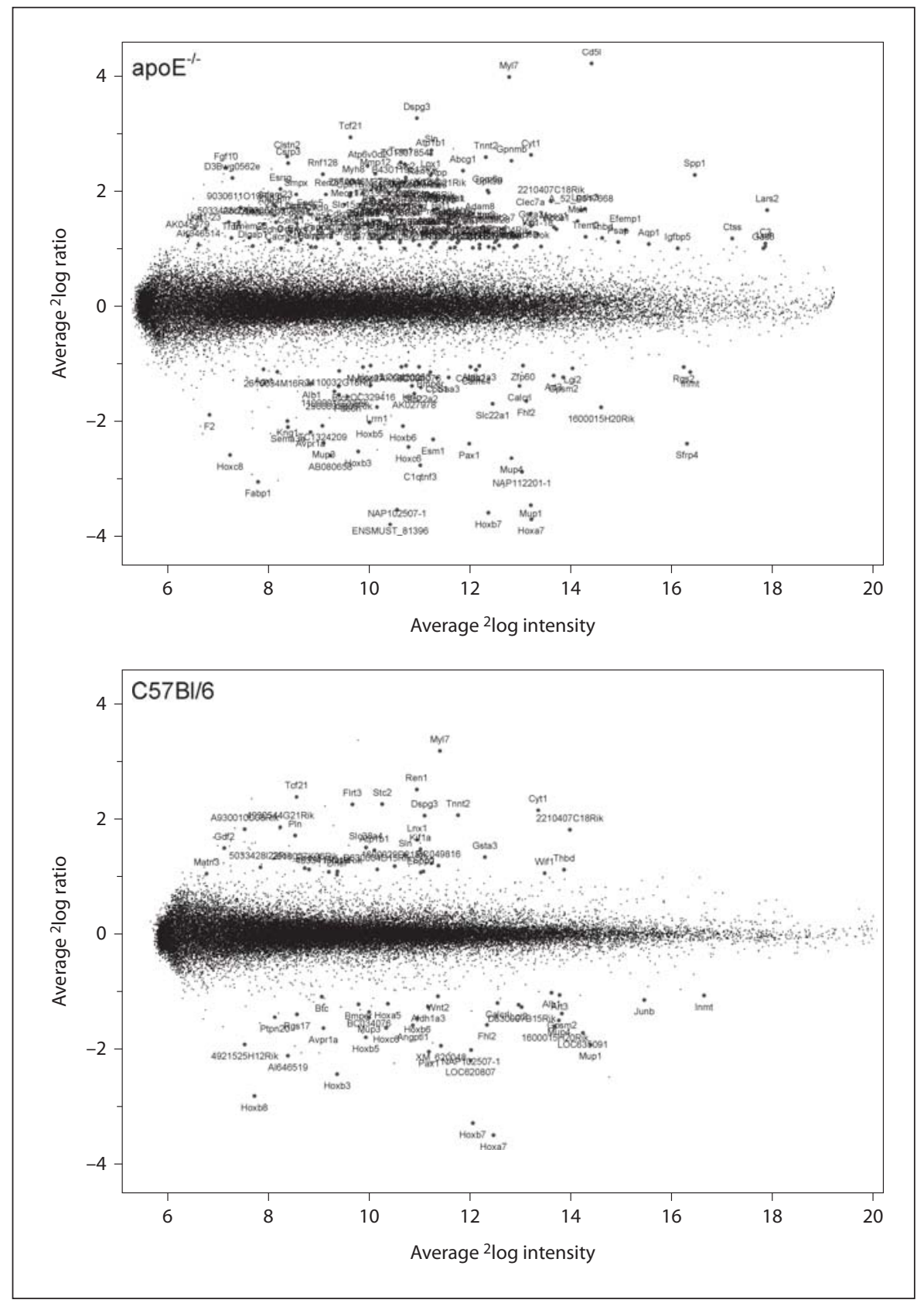

increased further at 18 and 22 months (fig. 1). The largest plaques were found in the aortic root, and the proximal (TA1) and distal (TA5) thoracic aorta segments. Furthermore, macroscopically visible lesions were present in the aortic arch, its side branches and around the carotid bifurcation. The CTA (TA2, TA3 and TA4) was usually not or only minimally affected. This very consistent observation led us to define the aortic root, aortic arch, TA1 and TA5 as 'atherosclerosis-prone' aorta segments, while TA2, TA3 and TA4 can be considered 'atherosclerosis-resistant' aorta segments. The 4-month-old apoE-/- mice used for the gene expression studies did not exhibit any visible lesions.

\section{Microarray}

From the 41,174 gene sequences evaluated, only 70 genes in $\mathrm{C} 57 \mathrm{Bl} / 6$ and 246 genes in apoE-/- mice showed differential expression between AA and CTA, as shown in ratio-intensity plots [20] (fig. 2). Increased expression 
('upregulation', $>2$-fold) in the AA was seen for 33 genes in $\mathrm{C} 57 \mathrm{Bl} / 6$ and for 188 genes in apoE-/- mice, while decreased expression ('downregulation', <0.5-fold) was seen for 37 genes in $\mathrm{C} 57 \mathrm{Bl} / 6$ and for 58 genes in apoE-/mice. Of the 33 genes upregulated in $\mathrm{C} 57 \mathrm{Bl} / 6$ mice, 20 genes were upregulated in apoE-/- mice as well, and 25 (of 37) genes downregulated in $\mathrm{C} 57 \mathrm{Bl} / 6$ mice were also expressed at a lower level in apoE-/- mice (table 2).

Among the 45 genes showing differential expression in both $\mathrm{C} 57 \mathrm{Bl} / 6$ and apoE-/- mice, most genes were related to development (13 genes), cell growth (8 genes) and transcription (10 genes, table 3). Only 7 (of 25) genes that were exclusively up- or downregulated in $\mathrm{C} 57 \mathrm{Bl} / 6$ mice could be linked to two specific processes: development (4 genes) and cell growth ( 3 genes). The other 18 genes are all involved in different biological processes (table 3 ).

The 33 genes that were only downregulated in the AA of apoE-/- mice were involved in signal transduction (7 genes), metabolism (3 genes) and immune responses (3 genes). The 168 genes that were specifically upregulated in the AA of apoE-/- mice could all be linked to processes involved in atherosclerosis, e.g. lipid metabolism, cell adhesion, immune response, cell death and ossification (table 3).

\section{Validation}

Six genes that showed differential expression in apoE-/- mice were selected for validation using the two RNA extracts of each individual mouse (fig. 3). RT-qPCR confirmed the overall increase or decrease in the AA for all genes in the 6 apoE-/- mice. Individual variability (fig. 3a-f) was surprisingly small for amyloid precursor protein (App), ATPase, $\mathrm{NA}^{+} / \mathrm{K}^{+}$transporting, $\beta_{1}$ polypeptide (Atp1b1) and Homeobox B7 (HoxB7), or rather large for secreted phosphoprotein 1 (Spp1), sarcolipin (Sln), and fatty acid-binding protein 1 (Fabp1). Upregulation of App and Atp1b1 occurred in both genders, but was more pronounced in males, as indicated by the interaction in the repeated-measures ANOVA (fig. 3). Upregulation of Spp1 in the microarray was caused by high expression in the AA of 2 mice, and the mean RT-qPCR values were statistically not different.

RT-qPCR of the selected genes in individual C57Bl/6 mice also confirmed the microarray results and indicated that 3 genes (Atp1b1, HoxB7 and Sln) were differentially expressed, in contrast to the others (fig. 4). Moreover, Deming regression showed a linear relationship between the ${ }^{2} \log$-transformed microarray and RT-qPCR results. Slope of regression line was 1.30 with a $95 \%$ confidence interval from 1.049 to 1.546 (fig. 4).
Table 3. Biological processes linked to the genes up- or dowregulated in an atherosclerosis-prone versus an atherosclerosis-resistant region in $\mathrm{C} 57 \mathrm{Bl} / 6$ mice only, in both strains (common) or solely in apoE-/- mice

\begin{tabular}{|c|c|c|c|c|c|c|}
\hline \multirow[t]{3}{*}{ Biological process } & \multicolumn{6}{|c|}{ Number of genes } \\
\hline & \multicolumn{2}{|c|}{$\mathrm{C} 57 \mathrm{Bl} / 6$} & \multicolumn{2}{|c|}{ common } & \multicolumn{2}{|c|}{ apoE-I- } \\
\hline & up & down & up & down & up & down \\
\hline Development & 3 & 1 & 4 & 9 & & 3 \\
\hline $\begin{array}{l}\text { Cell growth and/or maintenance } \\
\text { Cell proliferation } \\
\text { Cell differentiation }\end{array}$ & 2 & 1 & 3 & 5 & $\begin{array}{r}44 \\
8 \\
3\end{array}$ & 7 \\
\hline Transcription & - & 1 & - & 10 & 9 & - \\
\hline $\begin{array}{l}\text { Metabolism } \\
\text { Glycoprotein metabolism }\end{array}$ & 1 & - & - & - & $\begin{array}{r}16 \\
3\end{array}$ & 6 \\
\hline Lipid metabolism & - & - & - & - & 4 & - \\
\hline Cell adhesion & - & - & - & - & 15 & - \\
\hline $\begin{array}{l}\text { Immune response } \\
\text { Inflammatory response } \\
\text { Lymphocyte activation }\end{array}$ & - & - & - & - & $\begin{array}{r}12 \\
4 \\
3\end{array}$ & 3 \\
\hline Proteolysis and peptidolysis & - & - & - & - & 7 & - \\
\hline Cell death & - & - & - & - & 6 & - \\
\hline Cell motility & - & - & - & - & 4 & - \\
\hline Ossification & - & - & - & - & 3 & - \\
\hline Sum & 6 & 3 & 7 & 24 & 120 & 19 \\
\hline
\end{tabular}

Table 4. RT-qPCR of amyloid precursor protein (App), ATPase, $\mathrm{NA}^{+} / \mathrm{K}^{+}$transporting, beta 1 polypeptide (Atp1b1), fatty acidbinding protein 1 (Fabp1), homeo box B7 (HoxB7), sarcolipin (Sln), and secreted phosphoprotein 1 (Spp1) in CTA and AA in a second sample of apoE-/- and $\mathrm{C} 57 \mathrm{Bl} / 6$ mice

\begin{tabular}{lllrr}
\hline Strain & Gene & CTA & \multicolumn{1}{l}{ AA } & \multicolumn{1}{c}{$\mathrm{p}$} \\
\hline apoE-/- & App & $1.00 \pm 0.25$ & $1.88 \pm 0.08$ & 0.015 \\
& Atp1b1 & $1.00 \pm 0.25$ & $6.87 \pm 1.30$ & 0.010 \\
& Fabp1 & $1.00 \pm 0.66$ & $0.10 \pm 0.04$ & 0.048 \\
& HoxB7 & $1.00 \pm 0.21$ & $0.02 \pm 0.00$ & $<0.001$ \\
& Sln1 & $1.00 \pm 0.28$ & $18.66 \pm 5.65$ & $<0.001$ \\
& Spp1 & $1.00 \pm 0.45$ & $2.67 \pm 2.30$ & 0.496 \\
\hline C57B1/6 & App & $1.00 \pm 0.07$ & $1.09 \pm 0.12$ & 0.386 \\
& Atp1b1 & $1.00 \pm 0.19$ & $4.49 \pm 0.63$ & 0.002 \\
& Fabp1 & $1.00 \pm 0.44$ & $0.39 \pm 0.36$ & 0.361 \\
& HoxB7 & $1.00 \pm 0.05$ & $0.02 \pm 0.00$ & $<0.001$ \\
& Sln1 & $1.00 \pm 0.24$ & $6.37 \pm 1.38$ & 0.002 \\
& Spp1 & $1.00 \pm 0.22$ & $1.01 \pm 0.23$ & 0.879 \\
\hline
\end{tabular}

Results show $2^{-\Delta \Delta C t}$, mean $\pm S E M, n=5$; : paired Student's $\mathrm{t}$ test of $\Delta \Delta \mathrm{Ct}$ 


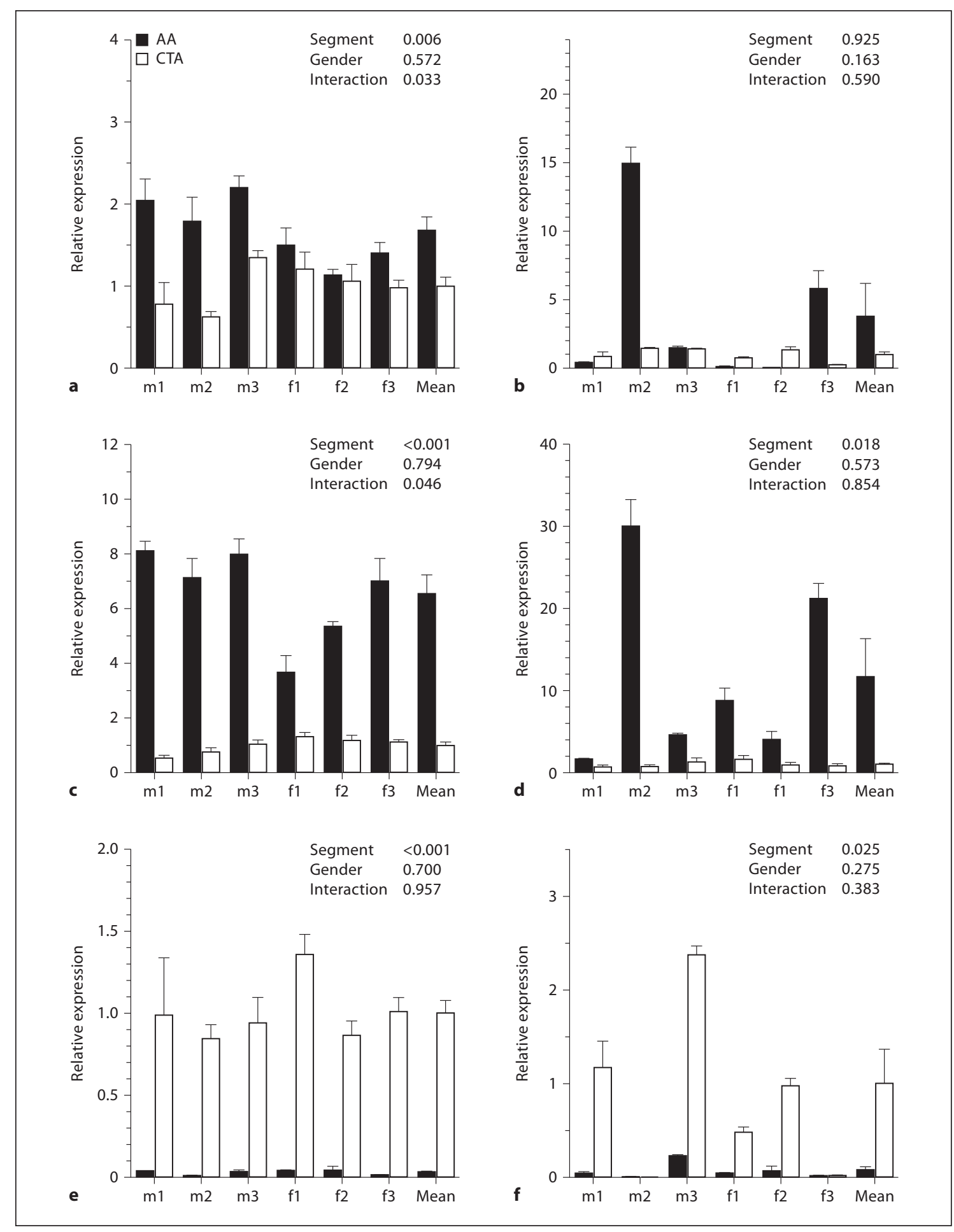

Fig. 3. RT-qPCR of genes in individual apoE-/- mice confirmed the microarray results: all 6 genes showed a comparable differential expression in AA and CTA (a-f). The results for amyloid precursor protein (a), ATPase (c) and homeobox B7 (e) were very consistent in all mice. Upregulation of amyloid precursor protein (a) and ATPase (c) was more pronounced in males, whereas upregulation of secreted phosphoprotein 1 (osteopontin, b) was mainly determined by 1 male (m2) and 1 female (f3), which also showed the largest difference for sarcolipin (d), and the lowest expression of fatty acid binding protein $1(\mathbf{f})$. Values are means \pm SEM of duplicate RT-qPCR runs (in individual mice), or means \pm SEM of the 6 mice; $m=$ male; $f=$ female. The significance of the effects of segment (CTA or TA), gender and their interaction in a repeated-measures ANOVA is reported. 
Fig. 4. Validation of microarray analysis versus RT-qPCR. Deming regression was performed on ${ }^{2}$ log-transformed microarray and RT-qPCR results to assess the relationship between the two methods. WT = C57Bl/6 mice.

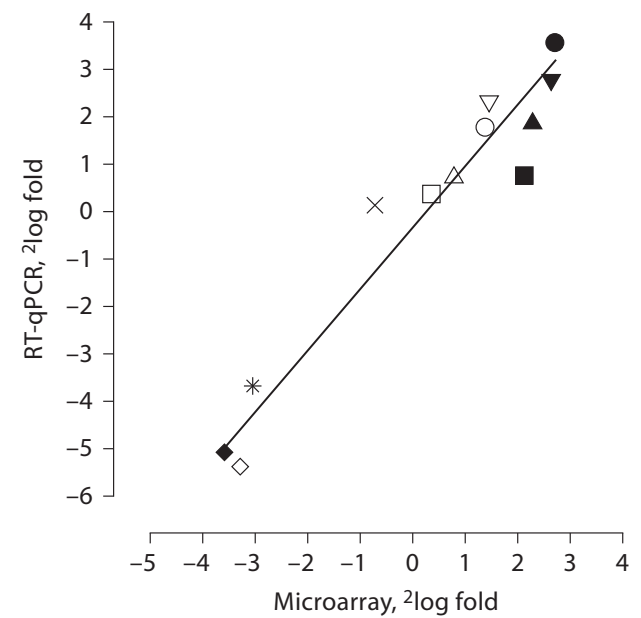

WT apoE-/-

- Amyloid precursor protein

A Secreted phosphoprotein 1

$\nabla$ ATPase, $\mathrm{Na}^{+} / \mathrm{K}^{+}$transporting, beta 1 polypeptide

- Homeobox B7

- Sarcolipin

* Fatty acid-binding protein 1
In view of the variation in Spp1, Sln and Fabpl expression between mice, we repeated the RT-qPCR analysis in a second sample of both strains (table 4). The results fully corroborated the first assay, including the rather variable expression of Spp1 in the AA of apoE-/- mice in comparison to $\mathrm{C} 57 \mathrm{Bl} / 6$ mice.

\section{Discussion}

The present study showed that in contrast to SMCs in the CTA, an atherosclerosis-resistant region, SMCs in the $\mathrm{AA}$, an atherosclerosis-prone region, displayed a proatherogenic phenotype even before the development of atherosclerotic lesions in hypercholesterolemic, but plaquefree apoE-/- mice.

In apoE-/- mice fed on normal chow, plaques were absent in all segments studied at 6 months; they were seen at 14 months and developed further after 18 and 22 months. The regional distribution of lesions within the aorta was very consistent. Apart from lesions in the aortic root and aortic arch, plaques were predominantly found in the most proximal and distal segments of the thoracic aorta, as previously reported [4-6]. The central region of the aorta was only minimally affected, even after 18 and 22 months. This makes the apoE-/- mouse an interesting model to study differences between atherosclerosis-prone and atherosclerosis-resistant regions.

Borang et al. [21] compared gene expression of vascular cells between an atherosclerosis-prone and an atherosclerosis-resistant region in 6- to 8-week-old apoE-/- and LDL receptor knockout mice using intact aortas. Because endothelial cells can mask genes that are overor underexpressed by SMCs and vice versa [22], we removed the endothelial cells before RNA isolation. Effective removal of the endothelium was confirmed by analyzing mRNA expression of CD31, an endothelial cell marker. We cannot claim, however, that we only looked at SMCs, since neurons and inflammatory cells are also present in the aortic wall. The number of subendothelial inflammatory cells may differ between atherosclerosis-prone and -resistant regions even in $\mathrm{C} 57 \mathrm{Bl} / 6$ wildtype mice [23]. Finally, the AA may have been contaminated bycardiomyocytes. To counteract theselimitations as adequately as possible, we compared gene expression between AA and CTA in both apoE-/- and C57Bl/6 mice. This enabled us to discriminate between differential expression due to location in the aorta $(\mathrm{C} 57 \mathrm{Bl} / 6$ and apoE-/- mice) and due to the location in combination with hypercholesterolemia (apoE-/- mice). The factor 'location in the aorta' comprises differences in cellular composition, embryological origin, and altered shear stress.

Genes that were differentially expressed in $\mathrm{C} 57 \mathrm{Bl} / 6$ and apoE-/- mice could be largely linked to transcription and development processes. This could be due to the different embryological origin of AA and CTA [24], or to biomechanical differences between the two regions [25]. Indeed, SMCs in culture can respond to biomechanical stimuli; disturbed flow decreases cell proliferation [13] while inducing fibroblast growth factor-2 secretion [26], cell contraction [27, 28], cytoplasmic calcium [29], cell 
alignment [30] and apoptosis [31]. However, endothelial cells serve as a 'buffer' between blood flow and SMCs, and it is uncertain to what extent SMCs are exposed to shear-induced forces in vivo. Nonetheless, it has been demonstrated that SMCs in atherosclerosis-prone regions are subjected to increased wall tension $[10,11]$. In vitro studies showed that pulsatile stretch can modulate SMC phenotype, and promote proliferation, depending on the degree of stretch [32], and SMC motility [33, 34] and alignment [35, 36], and induce apoptosis [37]. Moreover, stretch of isolated blood vessels stimulates protein synthesis and contributes to the maintenance of the contractile SMC phenotype [38].

It is also possible that the differential gene expression in the medial SMCs is driven by changes in the endothelial cells. It has been reported that endothelial cells in atherosclerosis-prone regions exhibit unique expression patterns [39-42] that shift their phenotype towards a sustained activated, proinflammatory state, and this might affect the underlying SMCs. For example, the transcription of endothelial nitric oxide synthase [43] is decreased in atherosclerosis-prone regions of the mouse aorta, and nitric oxide not only mediates SMC contractile responses but also determines alignment [32] and SMC proliferation in response to remodeling stimuli [44]. To what degree SMCs in vivo are influenced by changes in shear stress, wall tension, or paracrine endothelium-derived mediators has still to be elucidated. However, our study clearly demonstrated that gene expression of SMCs in vivo is different in the AA and CTA.

Regional differences alone are, however, not sufficient to induce atherosclerosis. Therefore, differences in gene expression in SMCs caused by the combination of hypercholesterolemia and location in the aorta are more likely to be involved in the onset of atherosclerosis. Indeed, classification of genes that were solely differentially expressed in apoE- $/-$ mice revealed that SMCs located in the AA showed increased expression of genes involved in proatherogenic processes, such as cell proliferation, differentiation, motility and adhesion, immune response and cell death. Moreover, the fact that genes involved in protein metabolism were upregulated suggests that SMCs in an atherosclerosis-prone region may already be shifting from a contractile to a synthetic phenotype $[45,46]$. It can be concluded that, in analogy to the endothelium, SMCs also showed a proatherogenic phenotype in the atherosclerosis-prone region before the actual formation of atherosclerotic lesions.

Distinct Transcription Profiles of Mouse Aortic SMCs

\section{Microarray Validation}

RT-qPCR of each individual mouse confirmed the microarray data for 6 genes in apoE-/- mice, though 3 genes [fatty acid binding protein 1 , secreted phosphoprotein 1 (osteopontin) and sarcolipin] exhibited large interindividual variation. For the other genes, the variation was much smaller. This stresses the importance of validating gene expression in each individual mouse that was used to create the RNA pool for the microarray to establish whether the mean expression is rather homogeneous or highly variable. It appeared that the value of the pooled population sample can be upregulated, while downregulation is apparent in some or even most individuals. Yet, in view of the interindividual variability of some genes, a second analysis of different mice was used to confirm the original data.

The microarray results for these 6 genes were also validated in the $\mathrm{C} 57 \mathrm{Bl} / 6$ mice using RT-qPCR of the original RNA extracts and in the second sample. Moreover, Deming regression showed that the microarray results were accurate compared to the RT-qPCR results. The slope of the regression, however, was slightly higher than 1 . This is probably explained by the increased dynamic range of RT-qPCR in comparison with microarray analysis.

The fact that 3 genes (Atplb1, HoxB7 and Sln) were similarly up- or downregulated in $\mathrm{C} 57 \mathrm{Bl} / 6$ and apoE-/mice indicates that their expression is mainly controlled by the location in the aorta rather than by the combination of location and biochemical stimuli (hypercholesterolemia, oxidative stress) in apoE-/- mice.

\section{Selected Genes}

Sarco/endoplasmic $\mathrm{Ca}^{2+}$ ATPase (SERCA) [47] is an enzyme that is important for $\mathrm{Ca}^{2+}$ homeostasis and contractile function in SMCs, but it has also been implicated in phenotypic switching $[45,46]$. Two regulators of SERCA (sarcolipin, phospholamban) showed increased expression in the AA. Sln was selected because it has been reported that mechanical stress (pressure overload through transverse aortic constriction) significantly decreased protein expression of Sln in mouse hearts [48]. In accordance with this finding, both mouse strains showed increased mRNA levels in the AA, demonstrating that the localization in the aorta, and therefore mechanical stress, differentially regulated Sln expression. However, the effect was greater in apoE-/- mice, and in this respect it is interesting that SERCA function appeared to decrease in aortic SMCs of old apoE-/- mice and could be restored by paraoxonase-1 transfection [49]. 
Atplb1 is an ion transporter that showed large upregulation in the AA of both strains. Na/K-ATPase has two major subunits $\left(\alpha_{1}\right.$ and $\left.\beta_{1}\right)$ that are both located in caveolae of cardiac myocytes [50]. It has been reported that $\mathrm{Na} / \mathrm{K}$-ATPase from the duodenum of spontaneously hypertensive rats is inhibited compared to that of WistarKyoto controls [51]. The physiological relevance of the differential expression of this ATPase in AA and CTA remains, however, unknown.

Six homeobox genes, a family of transcription factors that are linked to the establishment of a correct body plan [52], were differently expressed in AA and CTA of both strains. HoxB7 was selected, since Miano et al. [53] demonstrated that restricted expression of HoxB7 and -C9 distinguishes fetal from adult human SMCs. Moreover, overexpression of HoxB7 in C3H10T1/2 cells is able to differentiate this multipotent cell line into vascular SMCs or osteogenic or chondrogenic lineages [54], further evidence supporting the function of $\mathrm{Hox} B 7$ as a regulator of SMC phenotype. In addition, HoxB7 overexpression led to increased cell proliferation, a vascular SMC-like morphology and expression of early SMC markers calponin and smooth muscle protein $22-\alpha$ (smoothelin), but not of the intermediate SMC marker smooth muscle myosin heavy chain [55]. HoxB7 mRNA has been detected at higher levels in human atherosclerotic plaques than in normal arteries, implying that it might be involved in the switch of SMCs to a more immature phenotype during atherosclerosis [55]. However, our results showed reduced expression of HoxB7 in SMCs of the AA of both apoE-/and $\mathrm{C} 57 \mathrm{Bl} / 6$ mice. Whether HoxB7 is upregulated after plaque development remains to be determined.

App was selected because we previously showed that this protein is involved in the uptake and processing of platelets by macrophages around hemorrhagic microvessels in human plaques. App is stored in $\alpha$-granules of human platelets, and phagocytosis of blood platelets represents an alternative, non-LDL-dependent pathway of foam cell formation during atherosclerosis [56]. Moreover, during platelet phagocytosis, macrophages become activated, as indicated by the upregulation of proinflammatory genes, such as inducible nitric oxide synthase. App was essential for the activation of macrophages, since blood platelets of App-deficient mice were phagocytosed, but failed to activate macrophages [57]. The present study shows that App is expressed at a higher level in SMCs in the atherosclerosis-prone AA of apoE-/mice, and this warrants further study of its role in atherogenesis.
Sppl, better known as osteopontin, has emerged as a key factor in both vascular remodeling and development of atherosclerosis [58]. Osteopontin transgenic mice fed a high-cholesterol diet develop atherosclerotic lesions [59, $60]$, whereas osteopontin deficiency reduces atherosclerosis in apoE-/- [61] and apoE/LDL receptor-deficient mice [62]. In vitro overexpression of osteopontin promotes vascular SMC proliferation [63], and in vivo overexpression is associated with increased thickening of the media with aging and of the intima after arterial injury [64]. Finally, Iizuka et al. [65] reported that atmospheric pressure promotes osteopontin expression in human aortic SMCs. The microarray analysis demonstrated increased gene expression of osteopontin at the atherosclerosis-prone location, but both validation assays pointed to a large interindividual variance between mice. This is potentially interesting because it might be that apoE-/mice with higher expression of osteopontin in the atherosclerosis-prone region develop atherosclerosis sooner than mice with lower osteopontin expression. Indeed, it has been proposed that osteopontin may be a potential marker for predicting atherosclerosis in patients with essential hypertension [66].

Fatty acid-binding proteins (FABPs) are members of the superfamily of lipid-binding proteins. The primary role of all FABP family members is the regulation of fatty acid uptake and intracellular transport [67]. FABP1 has been shown to be involved in vascular SMC foam cell formation, and its gene expression increases in human SMCs grown in adipocyte differentiation medium for 21 days [68]. It has been reported, however, that hypertension suppressed the expression of Fabp mRNA. Our data also showed downregulation of FABP1 expression in the atherosclerosis-prone AA before plaque formation.

\section{Conclusion}

In 4-month-old $\mathrm{C} 57 \mathrm{Bl} / 6$ mice, the differential expression in the AA and CTA consisted only of a limited number of genes. In age-matched hypercholesterolemic but plaque-free apoE-/- mice, most of these genes showed the same tendency. However, apoE-/- mice showed a larger number of genes that were up- or downregulated in the atherosclerosis-prone AA. Those supplementary genes were related to processes involved in atherosclerosis, such as cell adhesion, proliferation, differentiation, motility and death, lipid metabolism and immune responses. It has previously been demonstrated that endo- 
thelial cells display a proatherogenic transcription profile in the mouse aorta before lesion development. This study shows that SMCs of an atherosclerosis-prone segment demonstrated a proatherogenic phenotype before the onset of atherosclerosis, and this could possibly facilitate local plaque development.

\section{Acknowledgments}

Research was supported by grants of the Fund for Scientific Research (FWO)-Flanders (Grant G.0627.06) and FWO-Flanders WOG Vascular Biology. The authors would like to thank Drs. P. Van Hummelen and J. Allemeersch (VIB MicroArrays Facility, www.microarrays.be) for performing the microarrays. W.M. is a postdoctoral fellow of the FWO-Flanders.

\section{References}

${ }_{1}$ Wissler RW, Strong JP: Risk factors and progression of atherosclerosis in youth. PDAY Research Group. Pathological Determinants of Atherosclerosis in Youth. Am J Pathol 1998; 153:1023-1033.

$\checkmark 2$ Corti R, Fuster V, Badimon JJ, Hutter R, Fayad ZA: New understanding of atherosclerosis (clinically and experimentally) with evolving MRI technology in vivo. Ann NY Acad Sci 2001;947:181-195.

3 VanderLaan PA, Reardon CA, Getz GS: Site specificity of atherosclerosis: site-selective responses to atherosclerotic modulators. Arterioscler Thromb Vasc Biol 2004;24:12-22.

-4 Nakashima Y, Plump AS, Raines EW, Breslow JL, Ross R: ApoE-deficient mice develop lesions of all phases of atherosclerosis throughout the arterial tree. Arterioscler Thromb 1994;14:133-140.

5 Reddick RL, Zhang SH, Maeda N: Atherosclerosis in mice lacking apo E. Evaluation of lesional development and progression. Arterioscler Thromb 1994;14:141-147.

-6 Crauwels HM, Van Hove CE, Holvoet P, Herman AG, Bult H: Plaque-associated endothelial dysfunction in apolipoprotein E-deficient mice on a regular diet. Effect of human apolipoprotein AI. Cardiovasc Res 2003;59: 189-199.

-7 Brooks AR, Lelkes PI, Rubanyi GM: Gene expression profiling of human aortic endothelial cells exposed to disturbed flow and steady laminar flow. Physiol Genomics 2002; 9:27-41.

-8 Dai G, Kaazempur-Mofrad MR, Natarajan S, Zhang Y, Vaughn S, Blackman BR, Kamm RD, Garcia-Cardena G, Gimbrone MA Jr: Distinct endothelial phenotypes evoked by arterial waveforms derived from atherosclerosis-susceptible and -resistant regions of human vasculature. Proc Natl Acad Sci USA 2004;101:14871-14876.

-9 Wasserman SM, Topper JN: Adaptation of the endothelium to fluid flow: in vitro analyses of gene expression and in vivo implications. Vasc Med 2004;9:35-45.

10 Carallo C, Irace C, Pujia A, De Franceschi MS, Crescenzo A, Motti C, Cortese C, Mattioli PL, Gnasso A: Evaluation of common carotid hemodynamic forces. Relations with wall thickening. Hypertension 1999;34:217221.
11 Jiang Y, Kohara K, Hiwada K: Association between risk factors for atherosclerosis and mechanical forces in carotid artery. Stroke 2000;31:2319-2324.

12 Lehoux S, Esposito B, Merval R, Tedgui A: Differential regulation of vascular focal adhesion kinase by steady stretch and pulsatility. Circulation 2005;111:643-649.

-13 Sterpetti AV, Cucina A, D’Angelo LS, Cardillo B, Cavallaro A: Shear stress modulates the proliferation rate, protein synthesis, and mitogenic activity of arterial smooth muscle cells. Surgery 1993;113:691-699.

14 Shigematsu K, Yasuhara H, Shigematsu H, Muto T: Direct and indirect effects of pulsatile shear stress on the smooth muscle cell. Int Angiol 2000;19:39-46.

15 Asada H, Paszkowiak J, Teso D, Alvi K, Thorisson A, Frattini JC, Kudo FA, Sumpio BE, Dardik A: Sustained orbital shear stress stimulates smooth muscle cell proliferation via the extracellular signal-regulated protein kinase 1/2 pathway. J Vasc Surg 2005;42:772_780 .

16 Dardik A, Yamashita A, Aziz F, Asada H, Sumpio BE: Shear stress-stimulated endothelial cells induce smooth muscle cell chemotaxis via platelet-derived growth factorBB and interleukin-1 $\alpha$. J Vasc Surg 2005;41: 321-331.

17 Lutgens E, Faber B, Schapira K, Evelo CT, van Haaften R, Heeneman S, Cleutjens KB, Bijnens AP, Beckers L, Porter JG, Mackay CR, Rennert P, Bailly V, Jarpe M, Dolinski B, Koteliansky V, de Fougerolles T, Daemen MJ: Gene profiling in atherosclerosis reveals a key role for small inducible cytokines: validation using a novel monocyte chemoattractant protein monoclonal antibody. Circulation 2005;111:3443-3452.

18 Paigen B, Morrow A, Holmes PA, Mitchell D, Williams RA: Quantitative assessment of atherosclerotic lesions in mice. Atherosclerosis 1987;68:231-240.

19 Livak KJ, Schmittgen TD: Analysis of relative gene expression data using real-time quantitative PCR and the $2(-\Delta \Delta \mathrm{C}(\mathrm{T}))$ Method. Methods 2001;25:402-408.
20 Burton DGA, Giles P.J., Sheerin ANP, Smith SK, Lawton JJ, Ostler EL, Rhys-Williams W, Kipling D, Faragher RGA: Microarray analysis of senescent vascular smooth muscle cells: a link to atherosclerosis and vascular calcification. Exp Gerontol 2009;44:659665.

-21 Borang S, Andersson T, Thelin A, Odeberg J, Lundeberg J: Vascular gene expression in atherosclerotic plaque-prone regions analyzed by representational difference analysis. Pathobiology 2004;71:107-114.

22 Lee RT: Functional genomics and cardiovascular drug discovery. Circulation 2001;104: 1441-1446.

23 Jongstra-Bilen J, Haidari M, Zhu SN, Chen M, Guha D, Cybulsky MI: Low-grade chronic inflammation in regions of the normal mouse arterial intima predisposed to atherosclerosis. J Exp Med 2006;203:2073-2083.

24 Wasteson P, Johansson BR, Jukkola T, Breuer S, Akyurek LM, Partanen J, Lindahl P: Developmental origin of smooth muscle cells in the descending aorta in mice. Development 2008;135:1823-1832.

25 Cunningham KS, Gotlieb AI: The role of shear stress in the pathogenesis of atherosclerosis. Lab Invest 2005;85:9-23.

26 Rhoads DN, Eskin SG, McIntire LV: Fluid flow releases fibroblast growth factor-2 from human aortic smooth muscle cells. Arterioscler Thromb Vasc Biol 2000;20:416-421.

27 Ainslie KM, Garanich JS, Dull RO, Tarbell JM: Vascular smooth muscle cell glycocalyx influences shear stress-mediated contractile response. J Appl Physiol 2005;98:242-249.

28 Civelek M, Ainslie K, Garanich JS, Tarbell JM: Smooth muscle cells contract in response to fluid flow via a $\mathrm{Ca}^{2+}$-independent signaling mechanism. J Appl Physiol 2002; 93:1907-1917.

29 Sharma R, Yellowley CE, Civelek M, Ainslie K, Hodgson L, Tarbell JM, Donahue HJ: Intracellular calcium changes in rat aortic smooth muscle cells in response to fluid flow. Ann Biomed Eng 2002;30:371-378.

30 Lee AA, Graham DA, Dela CS, Ratcliffe A, Karlon WJ: Fluid shear stress-induced alignment of cultured vascular smooth muscle cells. J Biomech Eng 2002;124:37-43. 
31 Apenberg S, Freyberg MA, Friedl P: Shear stress induces apoptosis in vascular smooth muscle cells via an autocrine Fas/FasL pathway. Biochem Biophys Res Commun 2003; 310:355-359.

32 Haga JH, Li YS, Chien S: Molecular basis of the effects of mechanical stretch on vascular smooth muscle cells. J Biomech 2006;40: 947-960.

-33 Li L, Chaikof EL: Mechanical stress regulates syndecan- 4 expression and redistribution in vascular smooth muscle cells. Arterioscler Thromb Vasc Biol 2002;22:61-68.

- 34 Li C, Wernig F, Leitges M, Hu Y, Xu Q: Mechanical stress-activated $\mathrm{PKC} \delta$ regulates smooth muscle cell migration. FASEB J 2003; 17:2106-2108.

35 Chen Q, Li W, Quan Z, Sumpio BE: Modulation of vascular smooth muscle cell alignment by cyclic strain is dependent on reactive oxygen species and P38 mitogen-activated protein kinase. J Vasc Surg 2003;37: 660-668.

-36 Standley PR, Cammarata A, Nolan BP, Purgason CT, Stanley MA: Cyclic stretch induces vascular smooth muscle cell alignment via NO signaling. Am J Physiol Heart Circ Physiol 2002;283:H1907-H1914.

\$37 Wernig F, Mayr M, Xu Q: Mechanical stretch-induced apoptosis in smooth muscle cells is mediated by $\beta 1$-integrin signaling pathways. Hypertension 2003;41:903-911.

- 38 Albinsson S, Nordstrom I, Hellstrand P: Stretch of the vascular wall induces smooth muscle differentiation by promoting actin polymerization. J Biol Chem 2004;279: 34849-34855.

- 39 Davies PF, Shi C, Depaola N, Helmke BP, Polacek DC: Hemodynamics and the focal origin of atherosclerosis: a spatial approach to endothelial structure, gene expression, and function. Ann NY Acad Sci 2001;947: 7-16.

40 Hajra L, Evans AI, Chen M, Hyduk SJ, Collins T, Cybulsky MI: The NF- $\mathrm{B}$ signal transduction pathway in aortic endothelial cells is primed for activation in regions predisposed to atherosclerotic lesion formation. Proc Natl Acad Sci USA 2000;97:9052-9057.

- 41 Passerini AG, Polacek DC, Shi C, Francesco NM, Manduchi E, Grant GR, Pritchard WF, Powell S, Chang GY, Stoeckert CJ, Jr., Davies PF: Coexisting proinflammatory and antioxidative endothelial transcription profiles in a disturbed flow region of the adult porcine aorta. Proc Natl Acad Sci USA 2004;101: 2482-2487.

42 Wara AK, Mitsumata M, Yamane T, Kusumi Y, Yoshida Y: Gene expression in endothelial cells and intimal smooth muscle cells in atherosclerosis-prone or atherosclerosis-resistant regions of the human aorta. J Vasc Res 2008;45:303-313.

-43 Won D, Zhu SN, Chen M, Teichert AM, Fish JE, Matouk CC, Bonert M, Ojha M, Marsden PA, Cybulsky MI: Relative reduction of endothelial nitric-oxide synthase expression and transcription in atherosclerosis-prone regions of the mouse aorta and in an in vitro model of disturbed flow. Am J Pathol 2007; 171:1691-1704.

44 Rudic RD, Shesely EG, Maeda N, Smithies O, Segal SS, Sessa WC: Direct evidence for the importance of endothelium-derived nitric oxide in vascular remodeling. J Clin Invest 1998;101:731-736.

45 Wamhoff BR, Bowles DK, Owens GK: Excitation-transcription coupling in arterial smooth muscle. Circ Res 2006;98:868-878.

-46 House SJ, Potier M, Bisaillon J, Singer HA, Trebak M: The non-excitable smooth muscle: calcium signaling and phenotypic switching during vascular disease. Pflügers Arch 2008;456:769-785.

47 Vangheluwe P, Schuermans M, Zador E, Waelkens E, Raeymaekers L, Wuytack F: Sarcolipin and phospholamban mRNA and protein expression in cardiac and skeletal muscle of different species. Biochem J 2005 389:151-159.

48 Shimura M, Minamisawa S, Yokoyama U, Umemura S, Ishikawa Y: Mechanical stressdependent transcriptional regulation of sarcolipin gene in the rodent atrium. Biochem Biophys Res Commun 2005;334:861-866.

49 Guns PJ, Van Assche T, Verreth W, Fransen P, Mackness B, Mackness M, Holvoet P, Bult $\mathrm{H}$ : Paraoxonase 1 gene transfer lowers vascular oxidative stress and improves vasomotor function in apolipoprotein E-deficient mice with pre-existing atherosclerosis. Br J Pharmacol 2008; 153:508-516.

50 Liu L, Askari A: $\beta$-Subunit of cardiac $\mathrm{Na}^{+}$ $\mathrm{K}^{+}$-ATPase dictates the concentration of the functional enzyme in caveolae. Am J Physiol Cell Physiol 2006;291:C569-C578.

51 Pereira CC, Shimuta SI, Ferreira AT, Paiva TB: Membrane potential and reactivity to potassium of duodenal smooth muscle from spontaneously hypertensive rats. Braz J Med Biol Res 1987;20:645-648.

52 Lewis EB: A gene complex controlling segmentation in Drosophila. Nature 1978;276: 565-570

53 Miano JM, Firulli AB, Olson EN, Hara P, Giachelli CM, Schwartz SM: Restricted expression of homeobox genes distinguishes fetal from adult human smooth muscle cells. Proc Natl Acad Sci USA 1996;93:900-905.

54 Bostrom K, Tintut Y, Kao SC, Stanford WP Demer LL: HOXB7 overexpression promotes differentiation of C3H10T1/2 cells to smooth muscle cells. J Cell Biochem 2000;78:210 221.

55 Gorski DH, Walsh K: The role of homeobox genes in vascular remodeling and angiogenesis. Circ Res 2000;87:865-872.

56 De Meyer GR, De Cleen DM, Cooper S, Knaapen MW, Jans DM, Martinet W, Herman AG, Bult H, Kockx MM: Platelet phagocytosis and processing of $\beta$-amyloid precursor protein as a mechanism of macrophage activation in atherosclerosis. Circ Res 2002, 90:1197-1204
57 Jans DM, Martinet W, Van De Parre TJ, Herman AG, Bult H, Kockx MM, De Meyer GR: Processing of amyloid precursor protein as a biochemical link between atherosclerosis and Alzheimer's disease. Cardiovasc Hematol Disord Drug Targets 2006;6:21-34

58 Seipelt RG, Backer CL, Mavroudis C, Stellmach V, Cornwell M, Seipelt IM, Schoendube FA, Crawford SE: Local delivery of osteopontin attenuates vascular remodeling by altering matrix metalloproteinase- 2 in a rabbit model of aortic injury. J Thorac Cardiovasc Surg 2005; 130:355-362.

-59 Chiba S, Okamoto H, Kon S, Kimura C, Murakami $M$, Inobe $M$, Matsui $Y$, Sugawara $T$, Shimizu T, Uede T, Kitabatake A: Development of atherosclerosis in osteopontin transgenic mice. Heart Vessels 2002;16:111-117.

60 Isoda K, Kamezawa Y, Ayaori M, Kusuhara M, Tada N, Ohsuzu F: Osteopontin transgenic mice fed a high-cholesterol diet develop early fatty-streak lesions. Circulation 2003;107:679-681.

61 Matsui Y, Rittling SR, Okamoto H, Inobe M, Jia N, Shimizu T, Akino M, Sugawara T, Morimoto J, Kimura C, Kon S, Denhardt D, Kitabatake A, Uede T: Osteopontin deficiency attenuates atherosclerosis in female apolipoprotein E-deficient mice. Arterioscler Thromb Vasc Biol 2003;23:1029-1034.

62 Strom A, Franzen A, Wangnerud C, Knutsson AK, Heinegard D, Hultgardh-Nilsson A: Altered vascular remodeling in osteopontindeficient atherosclerotic mice. J Vasc Res 2004;41:314-322.

63 Gadeau AP, Campan M, Millet D, Candresse T, Desgranges C: Osteopontin overexpression is associated with arterial smooth muscle cell proliferation in vitro. Arterioscler Thromb 1993; 13:120-125.

64 Isoda K, Nishikawa K, Kamezawa Y, Yoshida M, Kusuhara M, Moroi M, Tada N, Ohsuzu F: Osteopontin plays an important role in the development of medial thickening and neointimal formation. Circ Res 2002;91:77-82.

-65 Iizuka K, Murakami T, Kawaguchi H: Pure atmospheric pressure promotes an expression of osteopontin in human aortic smooth muscle cells. Biochem Biophys Res Commun 2001;283:493-498.

66 Kurata M, Okura T, Watanabe S, Fukuoka T, Higaki J: Osteopontin and carotid atherosclerosis in patients with essential hypertension. Clin Sci (Lond) 2006;111:319-324.

67 Chmurzynska A: The multigene family of fatty acid-binding proteins (FABPs): function, structure and polymorphism. J Appl Genet 2006;47:39-48.

68 Davies JD, Carpenter KL, Challis IR, Figg NL, McNair R, Proudfoot D, Weissberg PL, Shanahan CM: Adipocytic differentiation and liver $\mathrm{x}$ receptor pathways regulate the accumulation of triacylglycerols in human vascular smooth muscle cells. J Biol Chem 2005; 280:3911-3919. 